\title{
Editorial: Canopies in Aquatic Ecosystems: Integrating Form, Function, and Biophysical Processes
}

\author{
Julia E. Samson ${ }^{1 *}$, Marco Ghisalberti ${ }^{2}$, Matthew Philip Adams ${ }^{3}$, Matthew A. Reidenbach ${ }^{4}$, \\ Matthew H. Long ${ }^{5}$, Uri Shavit ${ }^{6}$ and Virginia B. Pasour ${ }^{7}$ \\ ${ }^{1}$ Department of Biology, University of North Carolina at Chapel Hill, Chapel Hill, NC, United States, ${ }^{2}$ Oceans Graduate \\ School, University of Western Australia, Perth, WA, Australia, ${ }^{3}$ School of Earth and Environmental Sciences, School of \\ Biological Sciences, and School of Chemical Engineering, University of Queensland, Brisbane, QLD, Australia, ${ }^{4}$ Department \\ of Environmental Sciences, University of Virginia, Charlottesville, VA, United States, ${ }^{5}$ Department of Marine Chemistry \& \\ Geochemistry, Woods Hole Oceanographic Institution, Woods Hole, MA, United States, ${ }^{6}$ Department of Civil and \\ Environmental Engineering, Technion Israel Institute of Technology, Haifa, Israel, ${ }^{7}$ Army Research Office, Durham, NC, \\ United States
}

Keywords: fluid dynamics, ecosystem engineering, coral, algae, canopy, mass transport, light availability, nutrient cycling

\section{Editorial on the Research Topic}

\section{Canopies in Aquatic Ecosystems: Integrating Form, Function, and Biophysical Processes}

\section{OPEN ACCESS}

Edited and reviewed by: Angel Borja,

Technological Center Expert in Marine and Food Innovation (AZTI), Spain

${ }^{*}$ Correspondence: Julia E. Samson juliasamson@mac.com

Specialty section:

This article was submitted to Marine Ecosystem Ecology,

a section of the journal

Frontiers in Marine Science

Received: 28 September 2019

Accepted: 29 October 2019

Published: 15 November 2019

Citation:

Samson JE, Ghisalberti M

Adams MP, Reidenbach MA, Long MH, Shavit $U$ and Pasour VB (2019) Editorial: Canopies in Aquatic

Ecosystems: Integrating Form, Function, and Biophysical Processes.

Front. Mar. Sci. 6:697.

doi: 10.3389/fmars.2019.00697
This Research Topic presents new research investigating the coupling between physical (fluid dynamics, mass transport, and light availability) and biological (nutrient cycling, particle transport, ecosystem structure, and biodiversity) processes in aquatic canopies. The starting point for this topic was the observation that our notion of "canopy" in the aquatic sciences, in contrast to that of our terrestrially-focused colleagues, remains underdeveloped. Forest canopy studies have been considered a new field of science (Nadkarni et al., 2011) and the concept of forest canopy research is clearly documented in the literature (Barker and Pinard, 2001; Nadkarni, 2001; Lowman, 2009); we have not found similar mentions of the canopy concept in aquatic studies. Over the past decade, however, there has been an increase in the number of studies on underwater canopies, as well as a shift toward more multidisciplinary studies that consider more than just the physical impacts of the canopy's presence (Ackerman, 2007; Nepf et al., 2007; O'Brien et al., 2014).

Through this Research Topic, we provide a platform to explore the various physical and ecological impacts of aquatic canopies on the broader environment. We considered a fairly broad definition of canopy and did not restrict the concept to macroscale algae and corals. Any biological or physical entity displaying canopy-like characteristics (notably resistance to flow in the water column) is of interest for understanding canopy impacts. Additionally, we acknowledge that underwater canopies are not usually static structures but display dynamic behavior and can change over time and space.

An important goal of this Research Topic was to start integrating different (methodological) approaches and discipline-specific viewpoints to develop a more holistic view of how canopies shape their ecosystems. Oftentimes, studies have focused on a single aspect of the canopy, creating a one-dimensional view of its function in a given ecosystem, for example as a flow regulator (Nepf and Vivoni, 2000; Ghisalberti and Nepf, 2009) or as a photosynthetic structure (Binzer et al., 2006). Understanding the strong and inherent coupling between a canopy's physical and biological impacts, however, would provide much more insight into the importance and function of canopies in aquatic ecosystems.

The manuscripts we received were diverse in the topics they treated as well as their aims and approaches. Several papers in our collection investigated canopies from a mechanistic point of view, looking at the effects of canopy structure on flow and the resulting ecosystem impacts. 
Starting at the sub-meter scale, van Rooijen et al.'s work on predicting drag forces in canopies offers a detailed understanding of canopy-flow interactions. The authors provide a robust tool to quantify canopy flow resistance across a range of canopy types (emergent or submerged, rigid or flexible). Their model will prove to be useful in further studies requiring accurate drag quantification in canopy environments, for example when studying reduced in-canopy flow environments or measuring the impact of the canopy on sedimentation.

At the canopy level, Fonseca et al. considered the interactions between canopy-forming organisms and their environment (both biotic and abiotic factors). They examined the importance of shoot flexibility and shoot density in seagrass beds that are exposed to flow and how these parameters influence hydrodynamics, turbulence, sedimentation, and light penetration within the seagrass bed.

Moving up from the seagrass bed to the meadow scale, Reidenbach and Thomas show that seagrass canopies exert significant control over both wave height and hydrodynamic conditions at the sediment-water interface. Their findings suggest that the role of seagrass canopies in sedimentation and the (re-)suspension of sediment particles in the water column is not confined to the seagrass bed, but extends beyond and above it, impacting the ecosystem more generally.

A couple of papers in the Research Topic looked directly at the functional effects a canopy can have at the ecosystem level. An important impact of the canopy that was highlighted is the influence of algal canopies on local recruitment. As shown by Umanzor et al., low canopy densities favor the recruitment of more seaweeds whereas high canopy densities displayed a higher abundance of microphytobenthic (benthic diatoms and cyanobacteria) recruits. They conclude that smallscale biophysical interactions linked to seaweed morphologies and densities can have profound effects on the recruitment and settlement of new primary producers. These interactions are often overlooked but can have significant consequences on the dynamics of the overall ecosystem.

Shifting ecosystem dynamics have been observed in the seagrass beds of the Chesapeake Bay, where one seagrass species, Zostera marina, is being replaced in some locations by Ruppia maritima. French and Moore investigated how seagrass species, biomass, and density affected invertebrate communities and sediment properties. They found correlations between seagrass species and sediment coarseness, shoot density and invertebrate biodiversity, and between seagrass biomass and both invertebrate biodiversity and abundance. Although seagrass species might not directly influence which invertebrate species are found, changes in sediment coarseness and seagrass biomass could well-affect the fauna abundance as well as the physical conditions under which they thrive.

Other papers highlighted the importance of going beyond the existing boundaries between research communities. In their perspective article, Stevens and Plew call for more connection and exchange between biophysicists focusing on natural marine canopies and those concentrating on "built" canopies (i.e., suspended aquaculture canopies) commonly used in (shell)fish farms. Though their purposes might differ (answering ecological vs. economic questions), both groups of researchers would benefit from learning more about each other's approaches and insights.

Taking a higher-level view, Folkard's comprehensive review provides guidelines for future exploration (including a request for physicists and ecologists to move toward each other in terms of methodology, reminding us of Stevens and Plew's call for more connection between research communities) and urges researchers to make the leap to the landscape-scale. Putting biophysical processes happening in aquatic canopies back in their landscape-wide context is crucial to support and inform management and conservation efforts since most of them take place at this scale.

In fact, a few papers in this collection have already taken up this call. Follett et al.'s contribution shows how seagrass bed parameters such as shoot density affect local hydrodynamics, which in turn affect pollen dispersion in the bed, and thus genetic variation in offspring (seeds) based on location height within the canopy. This paper also illustrates how modeling and experimental/field approaches can complement each other and lead to a more robust understanding of canopy systems.

Finally, on the largest scale, Ørberg et al. investigated the role of canopy-forming algae in the subarctic intertidal. Ascophyllum seaweeds were shown to facilitate higher species richness and recolonization by increasing habitat surface and complexity and modifying environmental stressors such as extreme temperature or desiccation. In the context of climate change, Ascophyllum nodosum's distribution range is expected to shift northwards, thus promoting the northward colonization of intertidal fauna in the Arctic.

From microscale hydrodynamic forces affecting sedimentation to allelic variation, invertebrate biodiversity, and the colonization of new habitats, the many impacts of aquatic canopies on the broader environment constitute a burgeoning area of research. Our understanding of what these canopies are, how they function, and how they influence entire ecosystems is rapidly expanding. Cross-disciplinary initiatives, including those presented in this topic, will continue feeding this momentum and lead us to new and important insights.

\section{AUTHOR CONTRIBUTIONS}

JS, MG, MA, MR, ML, and VP contributed input for the editorial. JS wrote the editorial. MG and MA gave extensive feedback on the draft. MG, MA, MR, ML, US, and VP gave feedback on the finalized version.

\section{FUNDING}

MA acknowledges funding support from Australian Research Council (ARC) Linkage Grant LP160100496 and the National Environmental Science Programme (NESP) Tropical Water Quality Hub. Funding to MR provided by the National Science Foundation (DEB-1237733 and DEB-1832221) and by a NSF CAREER grant (OCE-1151314). ML was supported by NSF OCE grant 1633951 . 


\section{REFERENCES}

Ackerman, J. D. (2007). Diffusivity in a marine macrophyte canopy: implications for submarine pollination and dispersal. Am. J. Bot. 89, 1119-1127. doi: 10.3732/ajb.89.7.1119

Barker, M. G., and Pinard, M. A. (2001). "Forest canopy research: sampling problems, and some solutions," in Tropical Forest Canopies: Ecology and Management, Forestry Sciences, Vol. 69, eds K. E. Linsenmair, A. J. Davis, B. Fiala, and M. R. Speight (Dordrecht: Springer), 23-38.

Binzer, T., Sand-Jensen, K., and Middelboe, A.-L. (2006). Community photosynthesis of aquatic macrophytes. Limnol. Oceanogr. 51, 2722-2733. doi: $10.4319 /$ lo.2006.51.6.2722

Ghisalberti, M., and Nepf, H. M. (2009). Shallow flows over a permeable medium: the hydrodynamics of submerged aquatic canopies. Trans. Porous Med. 78:309. doi: 10.1007/s11242-008-9305-x

Lowman, M. D. (2009). Canopy research in the twenty-first century: a review of arboreal ecology. Trop. Ecol. 50, 125-136.

Nadkarni, N. M. (2001). Enhancement of forest canopy research, education, and conservation in the new millennium. Plant Ecol. 153, 361-367. doi: 10.1023/A:1017546225607

Nadkarni, N. M., Parker, G. G., and Lowman, M. D. (2011). Forest canopy studies as an emerging field of science. Ann. For. Sci. 68:217. doi: 10.1007/s13595-0110046-6
Nepf, H. M., Ghisalberti, M., White, B., and Murphy, E. (2007) Retention time and dispersion associated with submerged aquatic canopies. Water Resour. Res. 43:W04422. doi: 10.1029/2006WR0 05362

Nepf, H. M., and Vivoni, E. R. (2000). Flow structure in depth-limited, vegetated flow. J. Geophys. Res. 105, 28547-28557. doi: 10.1029/2000JC9 00145

O’Brien, J. M., Lessard, J. L., Plew, D., Graham, S. E., and McIntosh, A. R. (2014). Aquatic macrophytes alter metabolism and nutrient cycling in lowland streams. Ecosystems 17, 405-417. doi: 10.1007/s10021-0139730-8

Conflict of Interest: The authors declare that the research was conducted in the absence of any commercial or financial relationships that could be construed as a potential conflict of interest.

Copyright (c) 2019 Samson, Ghisalberti, Adams, Reidenbach, Long, Shavit and Pasour. This is an open-access article distributed under the terms of the Creative Commons Attribution License (CC BY). The use, distribution or reproduction in other forums is permitted, provided the original author(s) and the copyright owner(s) are credited and that the original publication in this journal is cited, in accordance with accepted academic practice. No use, distribution or reproduction is permitted which does not comply with these terms. 